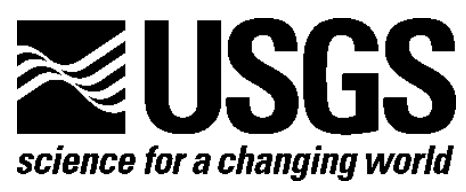

Prepared in cooperation with the U.S. Fish and Wildlife Service and the BaratariaTerrebonne National Estuary Program

\title{
Pilot Testing and Protocol Development of Giant Applesnail Suppression at Mandalay National Wildlife Refuge, Louisiana-July-October 2017
}

By Jacoby Carter and Sergio Merino

Open-File Report 2018-1041

U.S. Department of the Interior

U.S. Geological Survey 


\title{
U.S. Department of the Interior \\ RYAN K. ZINKE, Secretary
}

\section{U.S. Geological Survey \\ William H. Werkheiser, Deputy Director \\ exercising the authority of the Director}

\begin{abstract}
For more information on the USGS - the Federal source for science about the Earth, its natural and living resources, natural hazards, and the environment-visit https://www.usgs.gov/ or call 1-888-ASK-USGS (1-888-275-8747).
\end{abstract}

For an overview of USGS information products, including maps, imagery, and publications, visit https://store.usgs.gov/.

Any use of trade, firm, or product names is for descriptive purposes only and does not imply endorsement by the U.S. Government.

Although this information product, for the most part, is in the public domain, it also may contain copyrighted materials as noted in the text. Permission to reproduce copyrighted items must be secured from the copyright owner.

Suggested citation:

Carter, Jacoby, and Merino, Sergio, 2018, Pilot testing and protocol development of giant applesnail suppression at Mandalay National Wildlife Refuge, Louisiana-July-October 2017: U.S. Geological Survey Open-File Report 2018-1041, 17 p., https://doi.org/10.3133/ofr20181041.

ISSN 2331-1258 


\section{Acknowledgments}

Funding from this research came from the USGS Invasive Species Program, the Barataria-Terrebonne National Estuary Program, and the U.S. Fish and Wildlife Service. . 


\section{Contents}

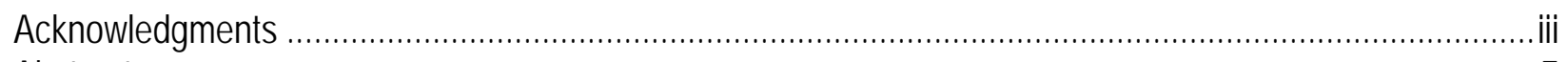

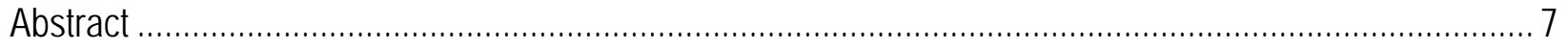

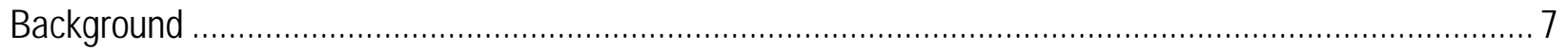

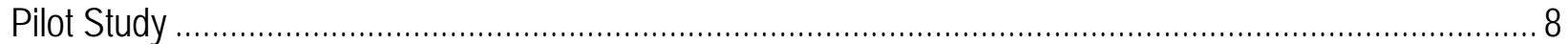

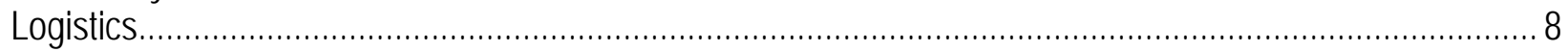

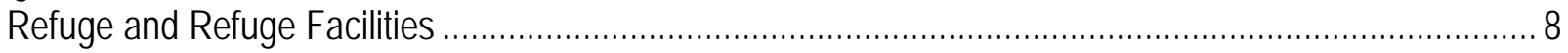

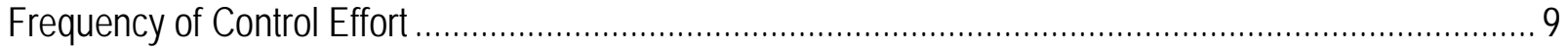

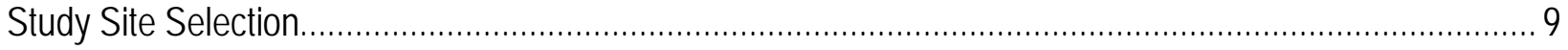

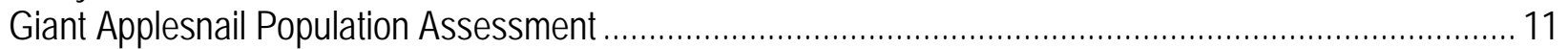

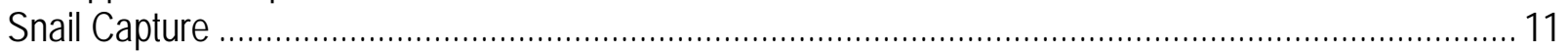

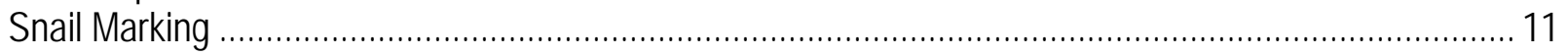

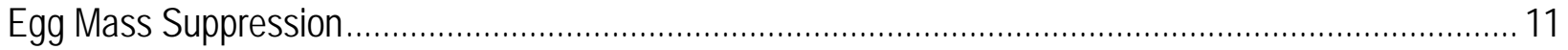

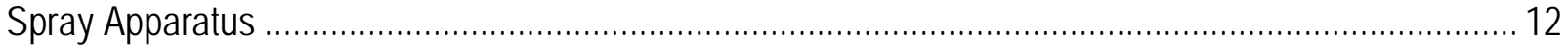

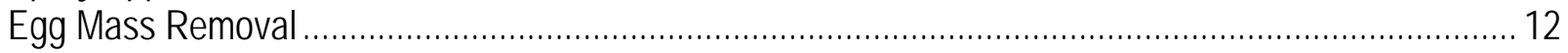

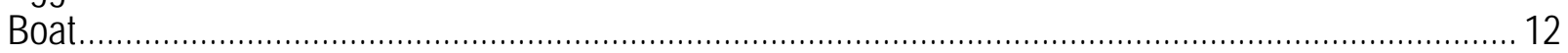

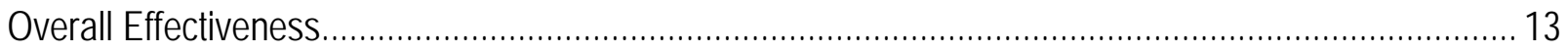

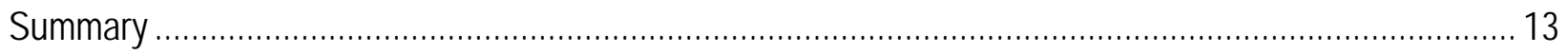

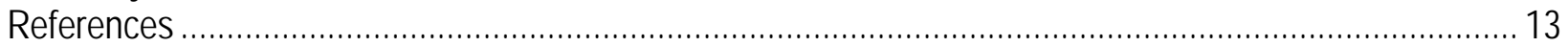

Appendix: Description of Spray Equipment Used to Remove and Destroy Egg Masses ........................... 15

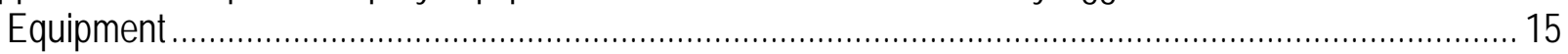

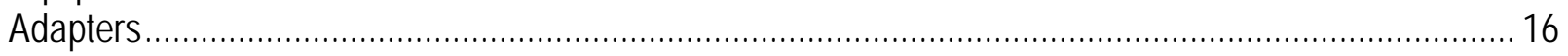

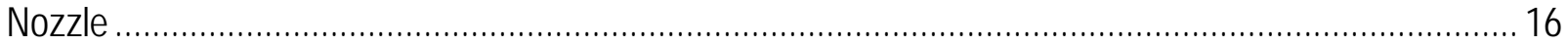

\section{Figures}

Figure 1.Mandalay National Wildlife Refuge, Louisiana. The study sites are circled in blue and the launch

site is circled in red.

Figure 1.1.2-inch suction hose with camlock adapter (left) and strainer cage with 3/8-inch holes (right).... 15

Figure 1.2.Spray hose setup with adapters, inline filter, 3/4-inch garden hose and spray nozzle.

Figure 1.3.Aluminum adjustable fan stream nozzle (garden hose thread / 1-inch national pipe straight hose

thread) 17 


\section{Conversion Factors}

International System of Units to U.S. customary units

\begin{tabular}{lcll}
\hline & Multiply & By & \multicolumn{1}{c}{ To obtain } \\
\hline & Length & & \\
\hline centimeter $(\mathrm{cm})$ & 0.3937 & inch (in.) \\
meter $(\mathrm{m})$ & 3.281 & foot (ft) \\
kilometer $(\mathrm{km})$ & 0.6214 & mile (mi) \\
kilometer $(\mathrm{km})$ & 0.5400 & mile, nautical (nmi) \\
meter $(\mathrm{m})$ & 1.094 & yard (yd) \\
\hline & Area & \\
\hline square kilometer $\left(\mathrm{km}^{2}\right)$ & 247.1 & acre
\end{tabular}




\title{
Pilot Testing and Protocol Development of Giant Applesnail Suppression at Mandalay National Wildlife Refuge, Louisiana-July-October 2017
}

\author{
By Jacoby Carter and Sergio Merino
}

\begin{abstract}
This report provides an overview of the pilot study and description of the techniques developed for a future mitigation study of Pomacea maculata (giant applesnail) at the U.S. Fish and Wildlife Service Mandalay National Wildlife Refuge, Louisiana (MNWR). Egg mass suppression is a potential strategy for the mitigation of the invasive giant applesnail. In previous studies at Langan Municipal Park in Mobile, Alabama (LMP), and National Park Service Jean Lafitte National Park-Barataria Unit, Louisiana (JLNP), we determined that spraying food-grade oil (coconut oil or Pam ${ }^{\mathrm{TM}}$ spray) on egg masses significantly reduced egg hatching. At JLNP we also developed methods to estimate snail population size. The purpose of this pilot study was to adapt techniques developed for previous studies to the circumstances of MNWR in preparation for a larger experiment whereby we will test the effectiveness of egg mass suppression as an applesnail mitigation tool. We selected four canals that will be used as treatment and control sites for the experiment (two each). We established that an efficient way to destroy egg masses is to knock them down with a high-velocity stream of water pumped directly from the canal. The traps used at JLNP had to be modified to accommodate the greater range of water-level fluctuation at MNWR. One of the three marking methods used at JLNP was selected for use at MNWR.
\end{abstract}

\section{Background}

Pomacea maculata (=Pomacea insularum) (giant applesnail) is an invasive freshwater snail, native to South America but widely introduced globally. Its distribution range has been expanding in freshwater wetlands across the Gulf of Mexico coast for over 10 years (Benson, 2018). In Laos, a sister species, Pomacea canaliculata (channeled applesnail), shifted the primary production in aquatic ecosystems from submerged aquatic vegetation to algae (Carlsson and Lacoursiére, 2005), and there is evidence that giant applesnails might do the same in the Everglades (Baker and others, 2010). In Louisiana, it has anecdotally been reported that, as giant applesnail populations have become established in south Louisiana, they have reduced submerged aquatic vegetation (Bonin, 2016), an important component in local wetland ecosystems (Chamberlain, 1959; Bardwell and others, 1962; Castellanos and Rozas, 2001). Another potential impact of snails on regional ecosystems is that they may prey upon on the eggs of frogs and toads (Karraker and Dudgeon 2014; Carter, personal observation). Predators that eat applesnails may control snail populations in some systems (Barr, 1997; Yamanishi and others, 2012), and indeed, giant applesnails have many potential predators (Hayes and others, 2015; Dorn and Hafsadi, 2016). In Louisiana we have documented two predators of adult snails, Alligator mississippiensis (alligator) (Elsey and others, 2017) and Procyon lotor (raccoon) (Carter and others, 2017). Apparently the regional predator community in the northern Gulf of Mexico has not reached an equilibrium with the giant applesnail as evidenced by the fact that giant applesnail densities continue to increase in areas where they have become established, and they are invading in new locations throughout the region (Benson, 2018). 
Female giant applesnails lay egg masses on plant stems or other substrates found above the water surface. Egg masses are aposematically colored, salmon color to pink, when freshly laid (Giglio and others, 2016). The size of giant applesnail egg masses vary, but they generally are 3 to 6 centimeters (cm) long and 1 to $2.5 \mathrm{~cm}$ wide, and on average they contain about 2,000 eggs (Barnes and others, 2008; Kyle and others, 2013). As the eggs mature the masses turn white, and eventually small brown hatchlings drop from their egg cases into the water. Our observations of giant applesnails in both field and laboratory settings indicated hatchlings begin emerge between 10 to 20 days after deposition with the last eggs hatching up to a week later. A female snail can go from freshly laid egg to laying eggs in 10 weeks (Sutton and others, 2017).

If we consider a founding population of a ten female snails on March 1, with only 1 percent survivorship from the egg to maturity and 10 percent weekly adult mortality, this hypothetical population would grow to over 5 million females, producing in excess of 270 million surviving progeny per week by the end of October. This magnitude of propagule pressure overwhelms local predator communities. As noted above, giant applesnail egg masses are relatively large, conspicuously colored, persist for 10 days or more, and are laid in areas generally accessible by boat. Because they are exposed, there is the potential to reduce giant applesnail propagule pressure by attacking the eggs. We plan to test the hypothesis that by significantly reducing giant applesnail propagule pressure, managers can help the native predator community to better control invasive giant applesnail populations just as they have helped control channeled applesnail populations elsewhere (Barr, 1997; Yusa and others, 2006; Yamanishi and others, 2012).

\section{Pilot Study}

This pilot study was undertaken to develop the techniques that are planned for in a future study to determine if giant applesnail egg mass destruction is an effective mitigation strategy. We did not test the hypotheses on egg mass suppression. We plan to do so in a follow on project in 2018. The techniques developed in this pilot study were built on methodologies developed for an egg mass suppression at Langan Municipal Park (LMP) in Mobile, Alabama, and a population study of giant applesnails at the National Park Service Jean Lafitte National Park, Barataria Unit, Louisiana (JLNP). However, techniques developed at LMP and JLNP required modifications for use at U.S. Fish and Wildlife Service Mandalay National Wildlife Refuge (MNWR) because the habitats of the three sites are different. LMP was a municipal lake with managed water levels. The sites at JLNP were permanently flooded bottomland hardwood forests. The study sites at MNWR are canals. This pilot study had three goals: (1) select study sites for the 2018 experiment, (2) determine the best method for egg mass suppression at MNWR, and (3) determine the best methodology for assessing the impact of the suppression program. Fieldwork was conducted from mid-July to the end of October 2017. This was not a formal study in the sense of Hypothesis-Methods-Experiment-Results-Conclusions. That form of the scientific method is planned for the 2018 field season. Instead, this pilot study reflected the need for a series of trial and error experiments with the techniques developed during previous studies to adapt them to the current study.

\section{Logistics}

\section{Refuge and Refuge Facilities}

MNWR is located south of Houma, Louisiana, in Terrebonne Parish and administratively is a unit of the Southeast Louisiana Refuge Complex (www.fws.gov/mandalay, accessed February 27, 2018). The refuge was established in 1996, has an area of 17.9 square kilometers $\left(\mathrm{km}^{2)}\right.$, and comprises freshwater marsh with ponds, levees, and constructed canals. Oil and gas wells and the Gulf-Intracoastal Waterway are important features in the area. The MNWR is only accessible by boat. The refuge has a remote office complex on Bayou Black Highway within $8 \mathrm{~km}$ of the boat launch. Boats and equipment are stored in buildings and sheds in a secure, gated area. We used the private boat launch at DaneCo Alligator Farm to deploy for all of our missions. 


\section{Frequency of Control Effort}

Giant applesnail eggs begin hatching 11 to 21 days after they are laid, with the eggs on the periphery of the egg mass hatching before the eggs in the interior. Eggs hatch out sooner when it is warmer and humid than when it is colder and drier (Carter, personal observation). Temperature effects on hatch out time were documented for channeled applesnails as well (Seuffert and others, 2012). Therefore, an effective egg mass suppression program should have a return frequency of 10 days or less in the summer months. In August and September our return times to the treatment sites varied between 4 and 9 days. In October our return times were every 10 to 16 days. Logistical problems that we encountered included inclement weather, flooding, mechanical problems with boats, and the availability of field staff. Eichhornia crassipes (water hyacinth) proved to be a problem for site access, particularly at Sunrise Canal (see below) where it was so thick that only airboats could be used. These challenges emphasized the importance of building in flexibility in treatment and sampling schedule.

\section{Study Site Selection}

Canals were chosen as study sites because they were easy to access, had deep water in the middle limiting the presence of emergent vegetation, defined edges, and limited reinvasion pathways. These features make egg mass suppression logistically easier to carry out and measure its impact. All the canals were in MNWR's southern unit (fig. 1): Specklebelly, Hog, Amy, and Sunrise Canals. Specklebelly and Amy were selected as control canals, and Hog and the south end of Sunrise canals were chosen as treatment canals. The canals were paired so that a control canal was near a paired treatment canal and off the same stem canal. Specklebelly was paired with Hog, and Amy was paired with Sunrise. The distance from the launch to the closest and farthest study site (Specklebelly) is $4 \mathrm{~km}$, and the distance to the farthest canal (Sunrise) is $7.5 \mathrm{~km}$. 


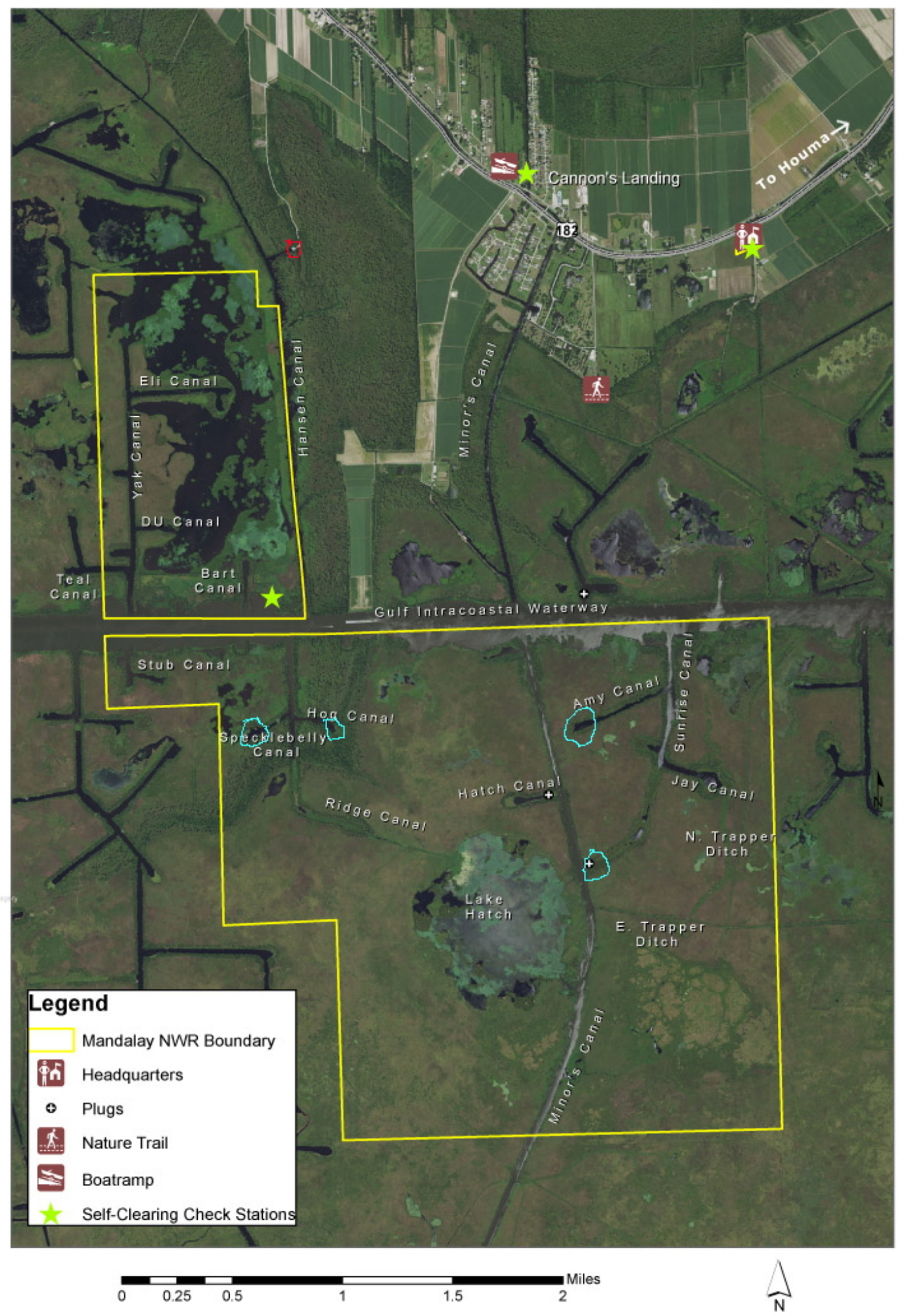

Figure 1. Mandalay National Wildlife Refuge, Louisiana. The study sites are circled in blue and the launch site is circled in red. 


\section{Giant Applesnail Population Assessment}

\section{Snail Capture}

Twelve traps were placed along the edges of the canals in three groups of four at the end, the right side, and the left side of the canal. The traps in each group were placed between 2 and 3 meters $(\mathrm{m})$ apart. The traps on either side of the canal were between 10 and $15 \mathrm{~m}$ from the end of the canal. The distance between the traps on the side of the canal depended on the width of the canal. The used traps were unbaited, pyramid style crawfish traps whose funnel entrances were widened to $7 \mathrm{~cm}$ diameter to accommodate large snails. We initially started off with 7 days between trap set and recover. However, capture rates were significantly higher at MNWR than at JLNP, and a 1-day return time between set and recovery was sufficient to capture enough snails for population estimation. The water levels fluctuated with a greater range at MNWR than at JLNP. In general, when the top of the trap was below the water surface the snails escape. To solve this problem we attached extenders to raise the top of the trap $1 \mathrm{~m}$.

\section{Snail Marking}

At JLNP we used two methods of individually marking snails and one batch marking method: (1) the individual marking methods were alpha-numeric tags (alpha tags) glued to the snail's operculum with a clear epoxy resin and radio frequency identification (RFID) tags epoxied on the shell near the apex; and (2) the batch marking method whereby snails were painted with different colors of fingernail polish to identify the location and day of first capture. After we recovered our initial trap sets, we decided to only use batch marking with fingernail polish for several reasons, with the primary reason being expense. Given the large number of snails that were being captured (10 to 40 snails per trap), individually marking the snails by using alpha tags or RFID tags would have been prohibitively expensive. Alpha tags cost $\$ 0.99$ per tag and RFID tags cost $\$ 1.60$ per tag. Based on our experience at JLNP fingernail polish remained on the shells for a month or more. A single $\$ 25$ bottle of fingernail polish can mark more than a hundred snails. The second reason for using batch marking is that fingernail polish is much faster to apply than either alpha tags or RFID tags, and over the short term there is less chance of losing the marks. We found that batch marking using the triple-catch method and a short (4 to 5 day) trapping window would allow us to make population estimates (Donnelly and Guyer, 1994). We also noted some additional observations that are relevant for population estimation. First, although we did recapture snails at the same trap location within a canal (the right side, the left side, or the end of the canal), we never recaptured snails at a location different from the initial capture location within the same canal (for example, a snail initially caught on the right side was never recaptured on the left side or the end of the same canal nor in a different canal). This observation indicates that snail movement within a canal is limited under normal circumstances. Second, because of the short time between recaptures, the population can be considered closed to reproduction. These observations, taken together, mean that for estimation purposes we can model the population effectively closed to immigration and reproduction during the sampling window.

\section{Egg Mass Suppression}

We considered several approaches to egg mass suppression. Our criteria were that egg mass suppression should be

- Easy to conduct from a boat; efficient; and effective at significantly reducing hatch out, removing egg masses from substrates, or directly destroying egg masses.

- Easy to implement with equipment that would be readily available to a refuge.

- Easy to implement within existing regulatory and administrative environment.

For example, the use of molluscides might require an environmental impact analysis and additional research to overcome regulatory barriers such as documenting the impacts on nontarget species and water quality. Permitting their use may require the involvement of multiple governmental agencies. 
Our original plan was to spray egg masses to suppress their development, as was tested at LMP and JLNNP. However, after visiting MNWR and reviewing the logistics we determined this might not be the best approach because of the following considerations:

(1) Oil sprayed egg masses remain where you sprayed them. On subsequent visits it would be difficult to distinguish between sprayed egg masses and egg masses laid since the last visit. Spraying every egg mass on every visit would be both inefficient and might become very expensive as the number of egg masses built up over the summer. In the lab we experimented with adding food dyes to the oil; however, the results were unsatisfactory in that, in our judgment, the dyes did not make sprayed egg masses stand out sufficiently from unsprayed egg masses. Furthermore, oil soluble dyes are expensive.

(2) Food grade oils for pest control seem to fall into a regulatory gray area. The U.S. Environmental Protection Agency (EPA) classifies the oils we proposed to use (coconut oil and canola oil) as "inert ingredients" and safe to use without a permit in combination with an active ingredient. The EPA also has a list of "active ingredients" that are regarded as safe to use without a permit. However, the EPA defines "active" ingredient as the substance impacting the pest regardless of mechanism. Even though the substance we originally proposed to use, food grade oils, are on the safe inert ingredient list, they were to be used as "active" ingredients, and food-grade oils are not on the safe active ingredients list. How the EPA will treat using safe, inert ingredients as active ingredients is unclear.

Because of the above considerations we decided to develop and test an alternative method of destroying egg masses. We settled on using water at high pressure to crush and knock egg masses into the water, using water taken directly from the canal. The eggs may then be crushed by the force of the spray, or fall into the water where they either drown or may be eaten (Horn and others, 2008; Ostrom and Chesnes, 2014). This method has several advantages over oil spraying:

- Because all egg masses are removed on each visit, egg masses found on subsequent visits have been laid since the last visit.

- $\quad$ Spraying egg masses with water requires no external agency approval or review.

- The oil used to spray the egg masses was projected to be a major expense. The water is free. The equipment, fuel and labor expenses between oil and water spraying should be similar.

\section{Spray Apparatus}

We tried several combinations of equipment over the course of three months (August through October 2017) before we found an effective setup. (see appendix for full description). The system we settled on has the following components: First, there is a wide gauge hose that runs from the water to a trash pump intake. The hose has a strainer on the water intake end to keep vegetation and debris from being sucked into the pump and clogging the spray nozzle. The pump outflow connects to a narrow gage hose that has a flow adjustable nozzle at its end. The pump pulls water from the canal and forces it through the nozzle at high pressure.

\section{Egg Mass Removal}

To remove the egg masses, the boat driver maneuvers the boat parallel to the shore of the canal while a second person runs the pump and uses the hose to knock down or crush the egg masses. The intake hose strainer must be monitored and periodically cleared of clogging vegetation and debris. Any observed egg mass is removed. During our trial period, it took on average about 40-60 minutes to treat 500 linear meters of a canal's perimeter depending on the boating conditions. The denser the water hyacinth coverage the longer it took to treat the canal.

\section{Boat}

We tried both airboats and boats with surface drive engines. When the canals were choked with water hyacinth only airboats were effective. 


\section{Overall Effectiveness}

We found this system effective at knocking off egg masses from whatever structures they were on from as far as $3 \mathrm{~m}$ away. The number of egg masses noticeable during the course of the pilot study decreased. However, this time frame also coincided with the reduction of snail egg laying activity. Dense water hyacinth made the process more difficult but not unworkable.

\section{Summary}

We tested and adapted methods for snail population assessment and egg mass suppression. We concluded that a batch marking with fingernail polish and using triple-catch protocol will be effective in estimating applesnail population sizes in this system. Using a high power water hose was effective for egg mass removal and will be less expensive than spraying with oil as originally proposed. Furthermore, the apparatus we assembled includes pumps, hoses, and other equipment that is the same or similar to what is already being used by national wildlife refuges to apply herbicides treatment for aquatic nuisance species. Thus, if future tests show that egg mass reduction is effective at mitigation of giant applesnail impacts, this technology will be both inexpensive and easy to implement at other refuges.

\section{References}

Baker, P., Zimmanck, F., and Baker, S.M., 2010, Feeding rates of an introduced freshwater gastropod Pomacea insularum on native and nonindigenous aquatic plants on Florida: Journal of Molluscan Studies, v. 76, p. 138-143.

Bardwell, J.L., Glasgow, L.L., and Epps, E.A., Jr., 1962, Nutritional analyses of foods eaten by Pintail and Teal in south Louisiana: Proceedings of the Annual Conference of the Southeastern Association of Game and Fish Commissioners, v.16, p. 209-217.

Barnes, M.A., Fordham, R.K., Burks, R.L., and Hand, J.J., 2008, Fecundity of the exotic applesnail, Pomacea insularum: Journal of the North American Benthological Society, v. 27, p. 738-745.

Barr, B.R., 1997, Food habits of the American Alligator, Alligator mississippiensis, in the southern Everglades: Coral Gables, Fla., University of Miami, Ph.D. Dissertation, 243 p.

Benson, A.J., 2018, Pomacea maculate: USGS Nonindigenous Aquatic Species Database, Gainesville, Fla., accessed February 27, 2018 at https://nas.er.usgs.gov/queries/FactSheet.aspx?SpeciesID=2633.

Bonin, P., 2016, Invasive applesnails wreak havoc in Orange Grove marsh: Louisiana Sportsman, accessed February 2, 2018 at http://www.louisianasportsman.com/details.php?id=9404.

Carlsson, N.O.L., and Lacoursiére, J.O., 2005, Herbivory on aquatic plants by the introduced Golden applesnail (Pomacea canaliculata) in Lao PDR: Biological Invasions, v. 7, p.233-241.

Carter, J, Merino, S., Prejean, D., and LaFleur, G., Jr., 2017, Observations of raccoon (Procyon lotor) predation on the invasive Maculata applesnail (Pomacea maculata) in southern Louisiana: Southeastern Naturalist, v. 16, no. 3, p. N14-N18.

Castellanos, D.L., and Rozas, L.W., 2001, Nekton use of submerged aquatic vegetation, marsh, and shallow unvegetated bottom in the Atchafalaya River Delta, a Louisiana tidal freshwater ecosystem: Estuaries, v. 24, no. 2, p. 184-197.

Chamberlain, J.L., 1959, Gulf coast marsh vegetation as food of wintering waterfowl: Journal of Wildlife Management, v. 23, no. 1, p. 97-102.

Donnell, M.A., and Guyer, C., 1994, Chapter 8. Estimating Population Size, pages 183-205 in Heyer, W.R., Donnelly, M.A., McDiarmid, R.W., Hayek, L-A.C., and Foster, M.S. (Eds.) Measuring and Monitoring Biological Diversity. Standard Methods for Amphibians. Smithsonian Institution Press. Washington D.C., USA. 364 pg.

Dorn, N.J., and Hafsadi, M., 2016, Native crayfish consume more non-native than native applesnails: Biological Invasions, v., 18, p. 59-167. 
Elsey, R.M., E. Ledet, E., and Carter, J., 2017, Alligator mississippiensis (American Alligator)—Novel nonnative prey item: Herpetological Review, v., 48, no. 3, p. 627-628.

Giglio, M.L., Ituarte, S., Pasquevich, M.Y., and Heras, H., 2016, The eggs of the applesnail Pomacea maculata are defended by indigestible polysaccharides and toxic proteins: Canadian Journal of Zoology, v. 94, no. 11, p. 777-785.

Hayes, K.A., Burks, R.L., Castro-Vazquez, A., Darby, P.C., Heras, H., Martín, P.R., Qiu, J.-W., Thiengo, S.C., Vega, I.A., Wada, T., Yusa, Y., Burela, S., Cadierno, M.P., Cueto, J.A., Dellagnola, F.A., Dreon, M.S., Frassa, M.V., Giraud-Billoud, M., Godoy, M.S., Ituarte, S., Koch, E., Matsukura, E.K., Pasquevich, M.Y., Rodriguez, C., Saveanu, L., Seuffert, M.E., Strong, E.E., Sun, J., Tamburi, N.E., Tiecher, M.J., Turner, R.L., Valentine-Darby, P.L., and Cowie, R.H., 2015, Insights from an integrated view of the biology of applesnails (Caenogastropoda: Ampullariidae): Malacologia, v. 58, no. 1-2, p. 245-302.

Horn, K.C., Johnson, S.D., Boles, K.M., Moore, A., Siemann, E., and Gabler, C.A., 2008, Factors affecting hatching success of golden applesnail eggs — effects of water immersion and cannibalism: Wetlands, v., 28, no., 2, p. 544-549.

Karraker, N.E., and Dudgeon, D., 2014, Invasive applesnail (Pomacea canaliculata) are predators of amphibians in South China: Biological Invasions, v.16, p. 1785-1789.

Kyle, C.H., Plantz, A.L., Shelton, T., Burks, R.L., 2013, Count your eggs before they invade: identifying and quantifying egg clutches of two invasive applesnail species (Pomacea): PLOS ONE 8(10): e77736 accessed at https://doi.org/10.1371/journal.pone.0077736.

Ostrom, A.S., and Chesnes, T.C., 2014, An assessment of submersion as a mechanical control technique of Pomacea maculata eggs in southern Florida USA: Natural Resources and Conservation, v. 2, no. 1, p. 6-10.

Seuffert, M.E., Saveanu, L., and Martin, P.R., 2012, Threshold temperatures and degree day estimates for embryonic development of the invasive applesnail Pomacea canaliculata (Caenogastropoda: Ampullariidae): Malacologia, v. 55, no. 2, p. 209-217.

Sutton, K.L., Zhao, L., and Carter, J., 2017, The estimation of growth dynamics for Pomacea maculata from hatchling to adult: Ecosphere, v. 8, no. 7, accessed March 14, 2018 at https: doi.org/10.10.02/ecs2.1840.

Yamanishi, Yoko \& Yoshida, Kazuhiro \& Fujimori, Noriomi \& Yusa, Yoichi. (2011). Predator-driven biotic resistance and propagule pressure regulate the invasive apple snail Pomacea canaliculata in Japan. Biological Invasions. 14:1343-1352, accessed March 14, 2018 at doi: 10.1007/s10530-011-0158-9.

Yusa, Y., Sugiura, N., and Wada, T., 2006, Predatory potential of freshwater animals on an invasive agricultural pest, the applesnail Pomacea canaliculata (Gastropoda: Ampullariidae), in southern Japan: Biological Invasions, v. 8, p. 137-147, March 14, 2018 at DOI: 10.1007/s10530-004-1790-4 


\section{Appendix: Description of Spray Equipment Used to Remove and Destroy Egg Masses}

\section{Equipment}

Several kinds of equipment were tested, and we will continue to experiment with the system. What follows was the most effective combination we have tested so far. A gas powered Honda WT20 “trash" pump was used to supply water. This pump has 2-inch inlet and outlet with about 180 gallon (about681 liters) per minute capacity.

The suction hose was about 5 meter (m) long with a strainer (fig. 1-1, right side) to keep vegetation from clogging the pump and nozzle. We hung this over the side of the boat into the water. In heavy submerged aquatic vegetation and floating leaved vegetation we often had to clear the intake strainer to keep a steady stream of water flowing.

To achieve greater spray range and knock down power, we used adapters to reduce the 2-inch hose to garden hose size (3/4 inch) (fig. 1-1, left side) and a fire hose nozzle with a fan/straight stream/off lever (fig. 1-2). This gave us a 3-5 m solid stream of water to knock down and destroy egg masses from the boat.

Although two people can effectively use this set up, we found that three people worked best: one to run the boat, one to handle the hose, and a third to help keep the intake clear and point out egg masses for the hose person. If the floating and (or) submerged vegetation was thick, we had to stop more often to reposition and clear the intake hose with strainer.

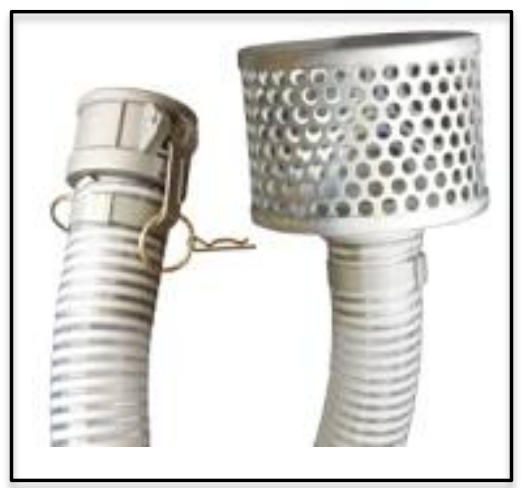

Figure 1.1. 2-inch suction hose with camlock adapter (left) and strainer cage with 3/8-inch holes (right). 


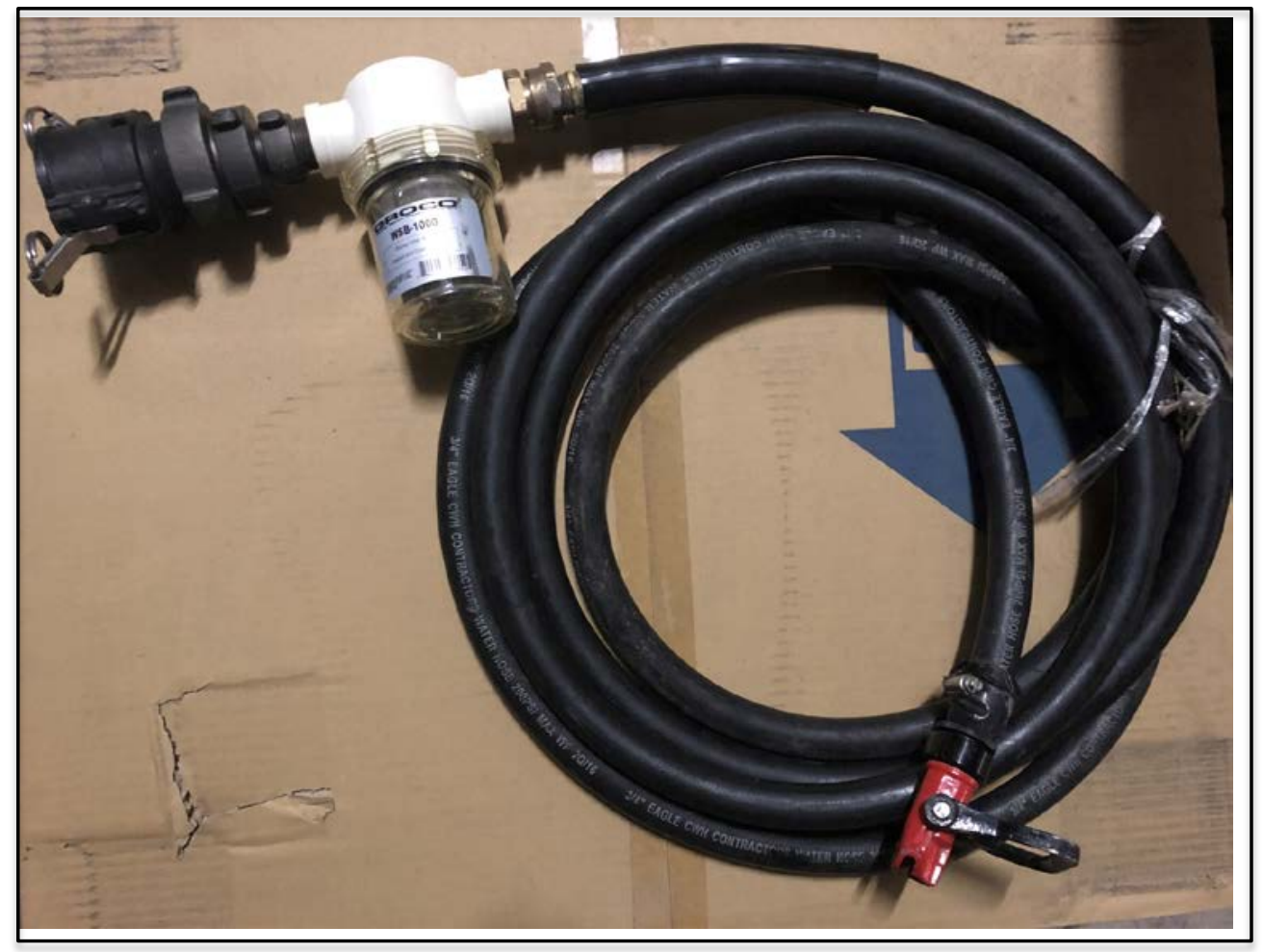

Figure 1.2. Spray hose setup with adapters, inline filter, 3/4-inch garden hose and spray nozzle.

\section{Adapters}

Two-inch camlock adapters were used to make it a quick release system to attach or remove the hoses (fig. 1-1). We then used a series of adapters to get down to the 3/4-inch garden hose thread size. We also had an additional inline filter (fig. 1-2), which was not necessary for use with the above nozzle because it didn't clog with debris coming through the 3/8-inch filter on the suction hose.

\section{Nozzle}

We tried a variety of fire hose nozzles from 2-inch adjustable fan/stream, smooth bore nozzles down to 1/2-inch orifice (requiring a separate on/off valve), and adjustable spray garden hose nozzles. We found that an aluminum adjustable fan stream nozzle (garden hose thread / 1-inch national pipe straight hose thread) gave us the best solid stream with knockdown power and easy on/off (fig.1-3). We would have liked to try smooth bore nozzles with a smaller orifice (3/8-inch and 5/16-inch are available in 1-inch National Hose thread), but with the cost of the adapters to go from 2 inches down to garden hose (3/4-inch) and the necessary separate inline on/off valve was cost prohibitive at the time because these nozzle are fire hose grade and rather expensive (about \$200-450). 


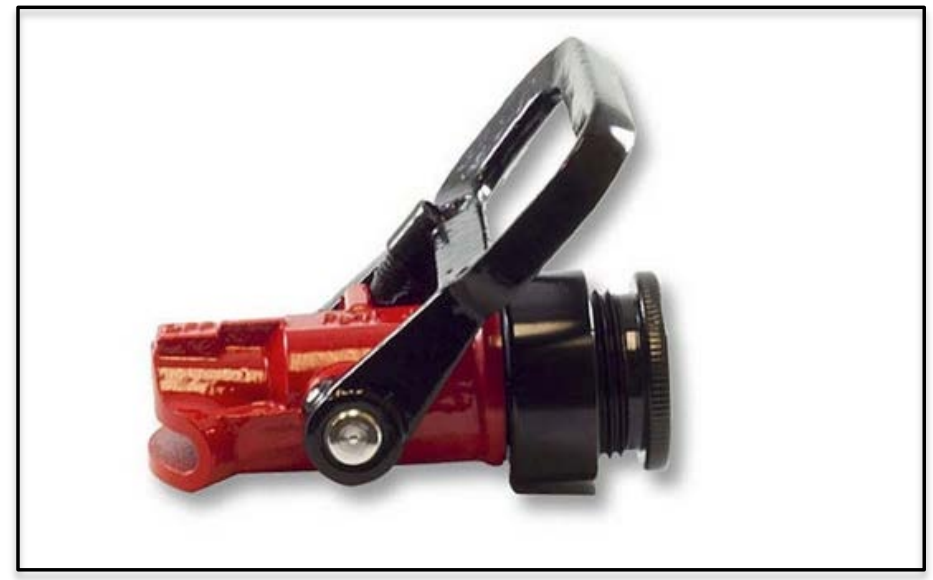

Figure 1.3. Aluminum adjustable fan stream nozzle (garden hose thread / 1-inch national pipe straight hose thread) 